\title{
DAVID Refugees and OWEN Responsibilities of Justice
}

\begin{abstract}
This essay develops, within the terms of the recent New York Declaration, an account of the shared responsibility of states to refugees and of how the character of that responsibility effects the ways in which it can be fairly shared. However, it also moves beyond the question of the general obligations that states owe to refugees to consider ways in which refugee choices and refugee voice can be given appropriate standing with the global governance of refuge. It offers an argument for the normative significance of refugee's reasons for choosing states of asylum and linked this to consideration of a refugee matching system and to refugee quota trading conceived as responsibility-trading, before turning to the issue of the inclusion of refugee voice in relation to the justification of the norms of refugee governance and in relation to the institutions and practices of refugee governance through which those norms are given practical expression.
\end{abstract}

Keywords: refugees; responsibility-sharing; justice; legitimacy; matching; quotas.

'We commit to a more equitable sharing of the burden and responsibility for hosting and supporting the world's refugees.'

'The New York Declaration marks a political commitment of unprecedented force and resonance. It fills what has been a perennial gap in the international protection system - that of truly sharing responsibility for refugees. ${ }^{2}$

\section{Introduction}

In the New York Declaration ${ }^{3}$, member states of the United Nations:

- expressed profound solidarity with those who are forced to flee;

- reaffirmed their obligations to fully respect the human rights of refugees and migrants;

- agreed that protecting refugees and the countries that shelter them are shared international responsibilities and must be borne more equitably and predictably;

1 UN General Assembly, New York Declaration for Refugees and Migrants: resolution / adopted by the General Assembly, 19 September 2016, A/RES/71/1 (2016), <http://www.refworld.org/docid/57ceb74a4.html> (Accessed: 4 October 2018).

2 UN High Commissioner for Refugees, Filippo Grandi, http://www.unhcr.org/uk/new-york-declaration-for-refugeesand-migrants.html (Accessed: 28th July 2018).

3 United Nations General Assembly (2016). 
- pledged robust support to those countries affected by large movements of refugees and migrants;

- agreed upon the core elements of a 'Comprehensive Refugee Response Framework'; and

- agreed to work towards the adoption of a global compact on refugees and a global compact for safe, orderly and regular migration.

The core elements of a 'Comprehensive Refugee Response Framework' are given in Part IV of the Declaration which reaffirms the 1951 Convention $^{4}$ and the 1967 Protocol $^{5}$ as the foundation of the international refugee protection regime (s.65), the legal framework of international refugee law, international human rights law and international humanitarian law (s.66), respect for the institution of asylum, the right to seek asylum and the principle of nonrefoulement (s.67), underlines the centrality of international cooperation to the refugee protection regime and commits to 'a more equitable sharing of the burden and responsibility for hosting and supporting the world's refugees, while taking account of existing contributions and the differing capacities and resources among States' (s.68), while recognizing 'that refugee camps should be the exception and, to the extent possible, a temporary measure in response to an emergency' (s.73). Of particular significance is that the Member States of the United Nations agreed that protecting those who are forced to flee is a shared international responsibility that calls for shared responsibility for the financing of refugee protection, the hosting of refugees, and the safe passage of refugees from transit to destination states. ${ }^{6}$

Although the preamble to the 1951 Convention Relating to the Status of Refugees recognised that the international refugee regime that it established was liable to place 'unduly heavy burdens on certain countries' and hence the need for "international cooperation," the increasing acknowledgment of the interdependencies of states and the complex relationships of immigration flows, global security, development and refugee protection, especially since the turn of the 21st century, has led to a recognition of the need for a more globalised approach aimed at durable and comprehensive solutions to refugee crises. However, the failure of prior projects framed in these terms such

4 UN General Assembly, Convention Relating to the Status of Refugees, 28 July 1951, United Nations, Treaty Series, vol. 189, p. 137 (1951), <http://www.refworld.org/docid/3beo1b964.html> (Accessed: 4 October 2018).

5 UN General Assembly, Protocol Relating to the Status of Refugees, 31 January 1967, United Nations, Treaty Series, vol. 606, p. 267 (1967), <http://www.refworld.org/docid/3ae6b3ae4.html> (Accessed: 4 October 2018).

6 UN General Assembly (2016).

7 United Nations, Convention Relating to the Status of Refugees, 1951 available online at http://www.ohchr.org/EN/ ProfessionalInterest/Pages/StatusOfRefugees.aspx (Accessed: 3 October 2018). 
as the Convention Plus Initiative (2003-5) ${ }^{8}$, a failure which signalled that Western states are not yet prepared to translate their verbal commitment to responsibility sharing into normative frameworks on international burden sharing'9 should register the sense in which the New York Declaration is both an achievement of international diplomacy and, at the same time, faces considerable challenges to the translation of its verbal commitments into concerted action. We may note, for example, that the crisis of solidarity - indeed, of European integration - engendered in the European Union, which might reasonably be thought to represent 'the best conditions that can be assumed under real world circumstances for an effective regional refugee protection regime'10 by the recent (and ongoing) refugee movements to the region indicates something of the scale of this challenge.

This article does not directly address the question of how to meet this challenge. Rather it is focused on the more limited preliminary task of clarifying the nature and scope of the shared responsibility that is at stake in the re-articulation of the relationship of the international community to refugees initiated by the New York Declaration and its implications for the sharing of that responsibility. ${ }^{11}$ The arguments that I offer will operate internal to the general framework of the New York Declaration, that is, they take the general terms and commitments expressed in that Declaration as fixed normative points around which my argument will pivot in order to develop principles of normative guidance. ${ }^{12}$

It is important to notice here that central to the Declaration is a focus on refugees as agents, not merely victims, and hence on the conditions that enable refugees to exercise agency in addressing the circumstances in which they find themselves - a shift represented in the movement from talking about refugee protection purely in terms of 'burden-sharing' to a conversation in which 'responsibility-sharing' is equally central'13 and topics such as 'refugee self-reliance' and 'refugee inclusion' are considerably more prominent. Yet this acknowledgment of refugee agency raises questions not only concerning the

8 UN Refugee Agency, Convention Plus Initiative (2003-5), <http://www.unhcr.org/uk/convention-plus.html> (Accessed: 4 October 2018).

9 Martin Gottwald, 'Burden Sharing and Refugee Protection' in Elena Fiddian-Qasmiyeh et al. (eds.) The Oxford Handbook of Refugee and Forced Migration Studies (Oxford: Oxford University Press, 2014), 525-37, p. 526.

10 Rainer Bauböck, Refugee Protection and Burden-Sharing in the European Union', Journal of Common Market Studies Vol. 56, No. 1 (2018), 141-156, p. 142.

11 It should be noted that the focus of the New York Declaration and of this article is on the remedial responsibility of the international community to refugees in general; this is quite compatible with specific states also having special reparative responsibilities in virtue of outcome-responsibility for a specific refugee crisis.

12 The features of this kind of methodological strategy are laid out in the Appendix to Joseph Carens, The Ethics of Immigration (Oxford: Oxford University Press, 2013) and may be regarded as ideal theorizing within limits specified by stated non-ideal constraints (here, the terms and commitments of the New York Declaration).

13 The language of 'burden-sharing' tends to be statist and technocratic and NGOs see it as projecting a highly partial and politically unhelpful picture of refugees as 'burdens' whereas the language of 'responsibility-sharing' is seen to stress the fact of responsibility and a view of refugees as agents not merely passive victims. 
responsibilities of global political society to refugees, centrally but not exclusively as an international community of states, but also of the role of refugee choices and refugee voice in the global governance of refuge and asylum. Consequently, the argument advanced in this article addresses not only the general remedial responsibilities of the international community towards refugees (i.e., those responsibilities that are independent of any reparative responsibilities that particular states owe to particular refugees), but also the place of refugee choices in a reasonably just refugee regime and of refugee voice in the legitimacy of global refugee governance. In the first section, I address the question of the duty of the international community to refugees within the terms of the New York Declaration and the implications of the content of this responsibility for how it should be shared. In the second section, I turn to address the normative significance of refugee choices and the implications of giving normative weight to these choices for a just refugee regime. In the final section, I address the place of refugee voice in relation to the legitimate governance of refuge and asylum. ${ }^{14}$

\section{Responsibilities to refugees}

What is due to persons entitled to refugeehood under the current international legal demarcation of that category of persons? The primary instruments of contemporary international refugee law are the 1951 Convention and 1967 Protocol. These instruments provide the basic international definition of the refugee:

One who owing to a well-founded fear of being persecuted for reasons of race, religion, nationality [as belonging to a "people"], membership of a social group or political opinion is outside the country of his nationality [as membership of a state] and is unable or, owing to such fear, is unwilling to avail himself of the protection of that country; or who, not having a nationality and being outside the country of his habitual residence [...] is unable, or, owing to such fear, is unwilling to return to it. $^{15}$

The normative basis of this specification of the refugee is that refugees

14 In some of my earlier work on refugees, I failed to appreciate adequately the significance of issues of refugee choices and refugee voice to the providing refugee protection in a way that acknowledges the dignity of refugees. I am grateful to Matt Gibney for deepening my appreciation of this issue, although he may not agree with where I go with it.

15 UN General Assembly (1951). 
are persons who have lost their political standing as members of a state. ${ }^{16}$ Persecution is distinct from the simple lack of protection of basic rights in virtue of the fact that it expresses and enacts the denial of the political standing of whose it targets. ${ }^{17}$ What though grounds the obligation of the international community to protect refugees so construed through the institution of asylum? Here we should note that the figure of the refugee is 'an inevitable if unintended consequence of the nation-state system; they are the result of erecting boundaries, attempting to assign all individuals to a territory within such boundaries, and then failing to ensure universal representation and protection. ${ }^{18}$ If we conceive of the international order of states as a particular regime of global governance, upheld and reproduced through the joint agency of states, then refugees are a normative problem for the legitimacy of this international order since, as a regime of governance, it cannot be justified to persons who are coercively subject to its norms but lack any effective membership (political standing) and hence also state protection. If this global structure of political rule is to be legitimate, then the international order of states has a duty to provide refugees with asylum, that is, to provide the refugee with the standing and protection that is otherwise denied them. The duty to provide asylum to refugees is not a humanitarian duty of rescue, it is a political obligation that states acquire in virtue of the legitimacy conditions of the global regime of governance that they uphold. ${ }^{19}$ Against this backdrop, let us then turn to the issue that is immediately raised by the focus on 'responsibility-sharing' in the New York Declaration, namely, 'responsibility for what?'. ${ }^{20}$

16 Matthew Price addresses refugeehood by taking up Rawls' stylised distinction between outlaw states and burdened societies. Price's point here concerns the distinctiveness of persecution. He writes:

Citizens of burdened societies lack protection of their basic rights, but they retain their standing as members. The appropriate stance of outsiders to burden societies is to lend assistance, not to condemn their failings. Asylum is an inappropriate tool for addressing the needs of those fleeing burdened societies. (Matthew Price, Rethinking Asylum (Cambridge: Cambridge University Press, 2009), p. 73)

By contrast, asylum as a mode of 'surrogate membership' in another state is the appropriate response for dealing with those of its citizens targeted by outlaw states as states which flout 'the requirements of international legitimacy by violating basic human rights - such as the peremptory human rights norms recognized by customary international law' (ibid., p. 73) since it provides these persecuted citizens whose very standing as members is being denied with protection 'in a manner that also expresses the condemnation that is deserved' (ibid, p. 73).

17 One could also develop this point in terms of dignity. On this view, the refugee is a figure whose exceptional status serves to reproduce the imagined reconciliation of an international order of sovereign states with a cosmopolitan commitment to the dignity of human persons.

18 Emma Haddad, The Refugee in International Society: Between Sovereigns (Cambridge: Cambridge University Press, 2008), p. 59.

19 For a defence of this 'political' view of refugeehood, see David Owen, 'In loco civitatis: on the normative structure of the international refugee regime' in Sarah Fine and Lea Ypi (eds.) Migration in Political Theory (Oxford: Oxford University Press, 2016a), 269-290.

20 In taking up this question in this way, I am not only taking the methodological decision not to address the wider debate concerning 'who is a refugee' but I am also, to keep the discussion focused, going to leave aside issues raised by the non-compliance of states within a scheme of responsibility-sharing. On this, see David Owen, 'Refugees, Fairness and Taking up Slack', Moral Philosophy and Politics 3/2 (2016b), 141-164. 
We can begin by noting that the institution of refugeehood presupposes, first, that persons presumptively entitled to refugee status have a right not to be prevented from advancing a legal claim to that status and, second, that persons who are legally recognised as having this status are entitled to be secure in their enjoyment of the protections that it affords. The former entails at the least that claimants ought not to be prevented from travelling to a place of refuge in which their claim to asylum can be fairly processed, and that they are protected from refoulement and have secure access to human rights, perhaps especially basic needs, while in transit to the place of claim-making and during consideration of their claim. The latter entails that a state of first refuge or of asylum (with the support by the international community) is both capable of, and disposed to, provide those protections that a state of first refuge or of asylum (as the agent of the international community) owes to refugees - first and most fundamentally, secure compliance with the duty of non-refoulement. What are these protections?

Any non-citizen resident in any state is entitled to protection of their basic human rights. A feature that distinguishes the refugee is that although they formally hold a nationality (in contrast to de jure stateless persons), they are demarcated from other resident non-citizens of a state by the fact that they do not have effective possession of the rights of external citizenship - the right to diplomatic protection and the right to return. These rights of external citizenship, respectively, support the protection of their human rights through the representations of their state of nationality to their state of residence in the context of a general reciprocal duty of states to secure the human rights of resident non-citizens, and provide them with a secure exit option that can be exercised at any time. The absence of effective possession of these rights entails that the international community has a special responsibility to ensure that refugees are secure in their enjoyment of human rights. We may reasonably view the UNHCR as a potential surrogate for the state of nationality in terms of the right of diplomatic protection, however, the absence of an equivalent to the secure exit option provided by the right to return means that refugees are particularly vulnerable in relation to the capacity and disposition of the state of first refuge or of asylum not simply to respect their human rights but to protect and fulfil them (to borrow Michael Blake's useful distinction). ${ }^{21}$ Recognizing this feature of the refugee's condition bears on two significant issues: refugee's access to membership of the state of asylum and refugee choices concerning the state to which to make application for asylum.

21 'Human rights, in a world split into distinct jurisdictions, impose distinct obligations on distinct political communities. In particular, we may invoke the standard tripartite distinction of obligations under human rights, to respect, to protect, and to fulfill. These three sorts of obligations call upon states to act in different ways toward different persons.' Michael Blake, 'Immigration, Jurisdiction, and Exclusion', Philosophy \& Public Affairs 41/2 (2013), 103-30, pp. 110-111. 
To take up the former, we can note Matthew Price's argument that if asylum is conceived as surrogate membership of a state, we should also acknowledge that there is good reason to adopt the claim that refugees should be granted accelerated access to citizenship of the state of asylum. Price argues that refugees are people who:

not only face a threat to their bodily integrity or liberty; they are also effectively expelled from their political communities. They are not only victims, but also exiles. Asylum responds not only to victims' need for protection, but also to their need for political standing, by extending membership in a new political community. ${ }^{22}$

In response to this argument, David Miller contends that it seems wrong to single out those who are escaping persecution and grant them permanent residence immediately on the grounds that having arrived they will all choose to identify politically with the society that takes them in.'23 Price's argument, he charges:

rests on the assumption that the causes that gave rise to persecution are such that the refugee will never be in a position to return in safety, whether because these causes themselves persist or because he has been mentally scarred by the experience and would experience psychological hardship if forced to return. Although this may be true in some cases, there will be other cases in which a change of regime means that those who have fled are more than willing to go back and pick up the threads of their previous lives. ${ }^{24}$

This disagreement draws attention to two points. The first is that while the international refugee regime addresses the civil, social and economic rights of refugees, it does not address the political rights of refugees; the fact that, in fleeing their state of nationality, they become 'politically stateless' in a global political society in which political standing is organised through effective possession of political membership of a state. We can understand Price's argument as motivated in part by the thought that it is integral to the expressive act performed by asylum to re-assert, in its condemnation of the persecuting state, the equal political standing of the refugee as a member of global political society. However, the point raised by Miller's criticism remains applicable. If we are to understand asylum as 'surrogate membership,' why should a grant of 'temporary citizenship' not suffice to meet this requirement? A temporary status that persists until the refugee is able to return to their state of nationality

22 Matthew Price, Rethinking Asylum (Cambridge: Cambridge University Press, 2009) p. 248.

23 David Miller, Strangers in our Midst (Cambridge, Massachusetts: Harvard University Press, 2016), p. 135-6.

24 David Miller (2016), p.133. 
or until they have resided in the state of asylum for a sufficient period to be entitled to apply for permanent citizenship? Alternatively, as Ruvi Ziegler has recently argued, this could be addressed by granting non-citizen voting rights (as well as secure travel and return rights) to refugees. ${ }^{25}$

Addressing this response to Price's call for rapid access to full and permanent membership in the state of asylum introduces the second point highlighted by this debate, namely, that it is a pervasive feature of refugee crises that their time-horizon is liable to be indeterminate - and the consequent position of refugees as persons who are 'situated in a condition of social and civic limbo, unable to commit to building a new life because they may be returned to the old, unable to commit to the old life because they may never be able to take it up once more. ${ }^{26}$ To be a refugee is, to a very significant degree, to lack an ability that is taken for granted by citizens who conduct their lives against the background of a right to secure residence of a state, namely, the ability to plan their futures, to make choices about the medium-term or long-term direction of their lives. The point here is not that such choice-making is not constrained by circumstance, but that the kinds of choices and, hence, plans available to an agent are significantly dependent on the institutions, practices and relationships that compose the social context that they inhabit. Everyday social contexts shape the horizon within which persons coherently conceive of, and act to realize, their future selves - and to inhabit a condition in which the social conditions of one's agency are constitutively open to being ruptured through repatriation is to lack a secure horizon in terms of which to engage in the activity of planning and shaping one's future. The cost of adopting 'temporary citizenship' or 'noncitizen voting rights' as a solution for the lack of political standing of refugees is that, in contrast to Price's proposal, it leaves this problem in place. This is a particularly significant issue for refugees because:

To be a refugee is not simply to be an individual who has lost the protection of her basic rights; it is to be someone deprived of her social world. It is to be someone who has been displaced from the communities, associations, relationships and cultural context that have shaped one's identity and around which one's life plan has hitherto been organised. Unsurprisingly, then, refugees often describe their experience as one of confusion, dispossession, and disempowerment. As one Somali refugee who sought asylum in Italy described his experience: 'there's a total void, a feeling of total disorientation.' 27

25 Ruvi Ziegler, Voting Rights of Refugees (Cambridge: Cambridge University Press, 2017).

26 David Owen, 'Citizenship and the marginalities of migrants' Critical Review in Social and Political Philosophy 16/3 (2013), 326-343, p. 334.

27 Matthew Gibney, 'Refugees and Justice between States', European Journal of Political Theory 14/4 (2015), 448-463, p. 459. 
Against the background of this basic feature of refugee experience, the issue of securing conditions of rebuilding a social life, of enabling autonomy, have a specific normative significance.

There are two relevant considerations here. The first concerns the responsibility of the international community to refugees in terms of securing conditions of life that enable the autonomous planning of their futures: to what extent - and for how long - can refugees be reasonably expected to inhabit a condition of social and civic limbo given the fact of dispossession of their prior social world? It is worth noting here that the laudable stress of the New York Declaration on encouraging refugee inclusion in the social and economic life of the state of asylum (in contrast to the use of refugee camps) can, when adequately supported, significantly increase the ability to refugees to exercise agency in relation to their immediate environment and to engage in autonomous choices with respect to their short-term future, yet ironically this very feature is liable to raise for refugees, perhaps even more acutely and immediately, awareness of the limitations of their autonomy with respect to choices oriented to the medium or long term. The second consideration concerns the responsibility of the international community with respect to the demands on states of asylum and their citizens in terms of providing access to citizenship for refugees. It is worth recalling that the lack of fair apportionment of refugee protection is a key contributor to the reluctance of states to admit refugees for whom, in virtue of the principle of non-refoulement, they thereby bear sole responsibility for what often amounts to indefinite protection. The proposal that refugees are rapidly granted permanent citizenship in the state of asylum is only likely to contribute further to such reluctance insofar as the distribution of refugees is perceived as unfair. More particularly, this suggests that fairness in the sharing of responsibility for refugee's is liable to encompass a significant degree of fairness in the distribution of the presence of refugees rather than, say, a clear division between states who host and state who pay.

Consider the example of Syrian refugees. We should note that as of January 2nd 2018, there were 5,481,218 registered refugees from Syria with just under 0.5 million based in refugee camps and the remainder distributed among the rural, peri-urban and urban populations of their host states. The largest host country is Turkey at almost 3.5 million, with just under a million in Lebanon, and another million divided across Jordan, Egypt and Iraq with Jordan having almost 0.7 million. Between April 2011 and October 2017, the number of asylum applications in the EU has been 996,204 with 64\% taken in Germany and Sweden, 20\% shared across Hungary, Austria, Netherlands, Greece, Denmark 
and $16 \%$ in all other member states. ${ }^{28}$ In sum, a group of poor-medium income states with a total population of c230 million have accepted more than five times the number of Syrian refugees as a medium-high income group of states with a total population of $\mathrm{c}_{510}$ million. Although such bald figures are liable to generate an intuitive sense of an unfair distribution of refugee protection, this might be at least partially countered by noting that the EU as a collective and many of its members as individual states are among the major donors to the UNHCR. For example, in 2016 the EU was the 2nd largest donor behind the USA, with Germany (3rd), UK (6th), Sweden (7th), Netherlands (9th) also in the top ten. ${ }^{29}$ However, if we accept the case for accelerated access to citizenship for refugees in their host state, the sense that this distribution does not represent a fair sharing of responsibility is acutely sharpened because it represents a significant unchosen transformation of the membership of some states and not of others.

Before we return to this issue and how sensibly to address it, we need to consider the second issue raised by the vulnerability of refugees to their state of asylum, namely, refugee choices concerning the state to which to make application of asylum. The point here is a simple one: if refugees are, in virtue of the effective absence of the exit option provided by a right to return to the home state (that is, the absence of a reasonable or acceptable exit option), particularly vulnerable to arbitrary exercises of private and public power in the state of asylum, then they have reason to seek asylum in states with both the capacity and disposition to ensure robust human rights protections. Put another way, there can be no obligation on refugees to apply for asylum in states that lack the capacity or disposition to ensure robust protections. This has two implications. First, refugees should be able to enjoy safe passage, to travel without unreasonable obstacles through transit states to the state of application for asylum, and the state of application should not be able to transfer refugees to another state that does not meet the relevant standards of human rights protection. Second, it suggests that a commitment to refugee responsibility sharing by the international community is linked to a wider shared responsibility to engage in capacity-building and disposition-building with respect to human rights protection, salient here both for sharing responsibility to tackle the source of refugee flows and to enable wider sharing of responsibility for hosting and including refugees.

28 All figures drawn from <http://data.unhcr.org/syrianrefugees/regional.php> (Accessed: 16th January 2018). 29 See <http://www.unhcr.org/uk/partners/donors/575e74567/contributions-unhcr-budget-year-2016-30september-2016.html> (Accessed: 16th January 2018). 
Drawing together the discussion of political rights or access to citizenship with the issue of refugee choices concerning the state of asylum application indicates that legitimate sharing of responsibility can reasonably be seen as involving two stages that relate to different capacities and hence to different divisions of responsibility. The first concerns immediate refuge where the key considerations are physical access (typically a function of geographic proximity in mass refugee events), security from refoulement, and basic needs protection. The division of responsibility to address this stage can be reasonably constructed in terms of the duty of the states to which refugees immediately flee (whether by foot, road, sea or air) to provide a place of first refuge and the duty of states generally to provide, according to their abilities and acknowledging any 'placebased' contribution they have made, the other resources needed to secure the basic needs of those who have fled. The second stage concerns asylum where the key concerns are those of general human rights protection, refugee inclusion, and pathways to civic integration. Here responsibility cannot so easily be separated between proximate 'hosts' and distant 'funders,' but rather needs to acknowledge that providing refugees with autonomy-enabling conditions calls for a different division of responsibility based on human rights security and integrative capacities.

It might be thought that this two stage distinction describes and perhaps justifies the current inequalities of distribution in refugee protection. As Gibney remarks:

One possible way of justifying these inequalities is by distinguishing between the burdens of Southern and Northern countries on the basis that the former simply 'host' refugees temporarily and the latter do the more onerous job of incorporating (or resettling) refugees into membership. This contrast appears to be borne out by the fact that many of the South's refugees are to be found in refugee camps, that is temporary places of residence from which refugees can return home after a short period of conflict or proceed to resettlement in a secure third country. ${ }^{30}$

However, as he continues:

Yet this distinction breaks down in practice. Life in a refugee camp is rarely a short-term affair. Conflicts that drag on for many years and the failure of states to provide sufficient resettlement places have resulted in a situation where some $54 \%$ of the world's refugees have been living in camps or without secure asylum for more than five 
years. Thus, while a distinction in roles between temporary host and resettlement states might be a feature of a future just redistributive scheme, this distinction cannot legitimise current inequalities between states. ${ }^{31}$

The underlying problem that Gibney identifies with the operation of the current refugee regime is that, given the fundamental principle of nonrefoulement, states that provide immediate refuge are dependent on the rest of the international community not only to provide the support needed for such refuge but also to secure the operation of the second division of responsibility in which those in places of first refuge are allocated to states of asylum and resettlement. Gibney draws out the implications of the failure of the current operation of the refugee regime thus:

As most refugees are created in the South, it is Southern countries that bear the brunt of responsibility because they are the countries refugees can mostly easily reach (at least in the first instance). Moreover, these inequalities are cemented in place by the measures that Western states use to prevent refugees arriving on their territory, like strict visa regimes, interdiction and carrier sanctions. These practices create a cordon sanitaire around the world's richest countries, keeping most of the world's refugees confined to the South. The consequences for refugees seeking asylum outside the poorer and often more insecure countries of the South are profound. The difficulty of reaching countries of the North where secure asylum could be had fuels demand for smugglers and makes refugee journeys more hazardous, as safer routes of entry are often sealed off. These barriers to entry tend to bias access to asylum in richer states to the physically agile (e.g. young adult refugees), the unencumbered (e.g. those not responsible for the caring of children) and those with access to the resources to pay smugglers and others who would facilitate their plight. Hence, inequities in the distribution of asylum across states provide a powerful constraint on the ability of refugees to seek asylum where it can be securely had. ${ }^{32}$

Addressing this problem points to the need for a global compact for refugees to secure adequate resettlement places and conditions of safe transit, but it should also draw attention to two other consequential points. First, that refugees are agents and, in the face of the inequities of the current regime, some refugees will engage in the dangerous work of contesting this regime, of refusing to be

31 Gibney (2015), p. 451-2. 32 Gibney (2015), p. 452. 
governed like this, at this cost, by undertaking hazardous journeys and, in doing so, demonstrating their dissent. Second, while the concerns of the global South are primarily driven by the sense that their geographical proximity to refugeeproducing states is effectively exploited by the global North in order to impose a disproportionate degree of responsibility for refugees onto them, and the fear of the global North is that, in the absence of non-arrival measure, they would receive a disproportionate share of the world's refugees (and that this would feed into populist anti-immigration politics within those states), the conjunction of these concerns is driving developments that undermine the fair and effective functioning of the regime and generate political problems for both groups of states as well as new challenges for the international community (such as the smuggling industry). It is these developments that can be seen as motivating the New York Declaration because, in relation to both of these issues, a crucial factor is the absence of any impartial international mechanism for working out the fair division of responsibility for refugees; an absence that, in leaving the fair sharing of responsibility indeterminate, enables domestic political groups or governments to shape and mobilize perceptions of unfairness for political advantage, and also leaves the international community lacking any adequate response to refugees who challenge the constraints that the regime places on them.

Moreover, precisely because the task of working out a fair distribution of responsibility is a complex one in which there is considerable space for reasonable disagreement even between actors operating in good faith, ${ }^{33}$ what is needed for an effective global compact is an impartial institutional process that allocates binding responsibilities across states. This is not to say that states or actors within those states will not dispute the fairness of particular allocations - and such an institutional process would require a dispute resolution mechanism but only that the institutionalization of this process provides a route to shaping the politics of refuge that reduces its potential as a source of international tension, as an amorphous vehicle of populist resentment, and offers the basis of a coherent way of responding to refugees.

In this section, my focus has been on what, in general, the international community of states owe to refugees, on the nature of the responsibility that states share and its implications for how that responsibility is shared. I have argued that this responsibility encompasses the provision of both immediate refuge and a state of asylum in which refugees should be entitled to rapid access to citizenship, where the criteria for the division of responsibility are distinct between these two requirements. I have further argued that the political 
challenge posed for a global refugee compact that embraces this view of the responsibilities of the international community to refugees and how it should be shared is best addressed through an international institution in which the fair allocation of responsibilities is given determinate and binding expression. The discussion thus far though has not considered the role of refugees in relation to the construction of a just and legitimate regime of global refugee governance and it is to this topic that I now turn.

\section{Refugee Choices}

In this section, I address the relation of refugee choices to the construction of a just scheme of global refugee distribution. The issue of refugee choice has already been touched on in the previous section where I argued that refugees have reason to seek asylum in states with both the capacity and disposition to ensure robust human rights protections and, hence, there can be no obligation on refugees to apply for asylum in states that lack the capacity or disposition to ensure such protections. However, we should also note that the integrative capacities of states are not independent of refugee choices, or the reasons for these choices. While refugees clearly have reason to favour states with robust human rights regimes, they may also have reason to favour either ranges of states or particular states on grounds that are intrinsic to realizing the ends of inclusion and integration. Thus, for example, refugees may have reason to favour a given range of states on the basis of its proximity to their home state, the language(s) they speak, its cultural similarity to their home state, the existence of a significant diaspora from their homeland in the state, the range of opportunities it offers given their education or occupational skills, its religious composition, or a number of other factors, where refugees may order and weight such factors quite heterogeneously. Refugees may also have reason to favour a particular state based on established family and/or friendship groups who are resident there. Given that it is a central ethical requirement of refugee resettlement to support political inclusion and social integration, these disparate grounds of refugee choices have normative significance and, hence, must be acknowledged; while in contexts where we have good reason to believe that such resettlement is likely to be long-term, this provides compelling grounds to weight refugee choices heavily in the distribution of refugees. ${ }^{34}$ There is, however, another reason why refugee choices must be acknowledged as having normative significance, namely, that such recognition of refugee as autonomous sources of claims to justification is the normative basis of the political institution of refugeehood. To exclude or ignore refugee choices is to fail to exhibit the moral respect for persons expressed in the claim to equal political standing (as

34 Gibney (2015), pp. 460-62 rightly stresses this point. 
effective membership of a state) of persons that the institution of refugeehood is designed to uphold in the face of state failures.

This does not entail that a refugee's choice of, or preference for, a particular state of asylum should be decisive since such a rule may be impossible to reconcile with a just distribution of responsibility for asylum across states. However, it does imply that any scheme of distribution should at least aim to accommodate the reasons for refugee preferences - and this should be widely plausible. Consider that most of the reasons that refugees have for favouring a given state are not unique to that state but would also be reasons for favouring a range of other states that exhibit the relevant feature(s), and hence the refugee's reasons for favouring a state are open to being satisfied even if the particular preference may not be. Those reasons that do pick out a specific state such as having existing family members resident in, or members of, that state are reasons that, in the context of a refugee's loss of their social world, should within the context of such a scheme be treated as having particular significance.

However, we should also note that the inclusion and integration of refugees is also partially dependent on the choices, and reasons for choice, of states concerning refugees for resettlement. One proposal that recognizes the heterogeneous preferences and diverse ranking of preferences of refugees and of states in relation to the end of inclusion and integration is the idea of 'a matching system' proposed by Will Jones and Alexander Teytelboym. ${ }^{35}$ The basic idea here is that, given sufficient global resettlement capacity, the legitimate preferences of states and of refugees, expressed as rank ordered sets, could be algorithmically matched:

Refugees, in principle, could submit their preferences from anywhere, saving them the risk of a dangerous journey and the extortion of people smugglers. This system involves no payment, works where there are quotas or other constraints, and can be made to work so that it is:

1. comprehensive - all refugees within the system are hosted somewhere (with quotas agreed by participating states adding up to the total number of refugees seeking places 'in the marketplace')

2. stable - refugees and countries do not end up dissatisfied with their choice and wanting to 're-match' by undertaking secondary movements

35 See Will Jones and Alexander Teytelboym, 'The Refugee Match' <http://www.europarl.europa.eu/cmsdata/109080/ The_refugee_match.pdf> (Accessed: 26th Jan 2018). 
3. efficient - no refugee can be made better off without making at least one other refugee worse off.

Finally, it can be made 'safe' for states and refugees to honestly reveal their true preferences. ${ }^{36}$

In the form advanced by Jones and Teytelboym, this matching system focuses on the state of asylum preferences of refugees and the types of refugee preferred by states (for example, whether they speak a major language of the state of asylum) - and this raises two issues.

First, the kind of preferences that should be the relevant focus. For example, the vast majority of Syrian refugees who have expressed a preference for a state of asylum in the EU have identified Germany as their first choice. There is, first, an issue concerning the formation of these preferences, that is, whether they have been formed through a reliable epistemic process. This issue becomes particularly pertinent as refugees move to lower ranked preferences where the informational basis on which the ranking is made may be poor. Acknowledging this issue links to a second point, that is, whether more general preferences or what I have described above as 'reasons for choices' - might provide a more robust basis for capturing what is valuable for refugees because less dependent on the refugee possessing accurate information about possible destination states. These more general value preferences could then be used in conjunction with epistemically robust indicators to generate a ranking of preferred states of asylum.

The second issue concerns the distinction between preferences and legitimate preferences. Notice first that it is an important point about this proposal that the preferences of states (or refugees) should play no role in determining who is eligible for resettlement. I have essentially bracketed that question so far by assuming a context in which all refugees who meet the relevant criteria for asylum are selected for resettlement, but in a context in which the available spaces for resettlement were less that the demand, it would be crucial to the fair functioning of this system that selection for resettlement was not shaped by state preferences and that only the resettlement of those who were selected (whether by lottery or by need or on some other basis) was done through such a matching scheme. Under such non-ideal conditions, respect for the equal standing of refugees requires that they each have a fair chance of resettlement, where the relevant determination of the idea of a fair chance (for example, selection of the basis of need) is justifiable to them. With this point in place,

36 Will Jones and Alexander Teytelboym, 'Choices, preferences and priorities in a matching system for refugees', Forced Migration Review online <http://www.fmreview.org/destination-europe/jones-teytelboym.html> (Accessed: 26th Jan 2018). 
we still face the issue of distinguishing preference and legitimate preferences - could a state, for example, legitimately express a preference for refugees who are Christians or who are highly educated or who are young? These features may, after all, be salient for supporting the goal of inclusion and integration in these states. Much here depends on the reasons for these preferences, for example, it would seem prima facie to be an expressive wrong for a state that had a religiously diverse citizenry to express a preference for refugees of a particular religion (unless perhaps as a way of supporting a minority religious group that faces social discrimination). However, there may be legitimate reasons for a developing state in need of skilled professionals to bolster its human rights or democratic infrastructure to express a preference for skilled workers or for a state with an age-imbalanced population (e.g., Italy, Germany) that weakens the sustainability of socially just relations within the state to prefer younger refugees. Given that the selection of those for resettlement is not affected by such choices, these preferences may be legitimate where they support goals in addition to inclusion and integration that we have independent reasons of justice to value.

In principle, then, matching systems provide a plausible mechanism for accommodating the legitimate preferences of refugees and of states. And we should note that such systems, as with any mechanism or process that takes refugee choices and reasons for choices as having normative significance, is itself an important expression of respect for, and enabling of, refugee autonomy. Notice though that the operation of a matching scheme supposes a pool of refugees selected for resettlement and a range of quotas for resettlement allocated to, and agreed by, states. Within the terms of such a scheme, a just distribution of refugees that respects the preferences of refugees and of states can be worked out. But it is also the case that the preferences of refugees could in principle be more fully satisfied if the quotas between states were changed in a way that enabled more refugees to achieve greater satisfaction of higher ranked preferences. For example, while the 90\% of Syrian refugees to the EU who rank Germany as their first preference cannot all have that preference satisfied, more could if Germany's quota increased. Are departures from a just distribution of refugee quotas to accommodate refugee preferences justifiable?

Here it is important to distinguish between two different types of departure from such a just distribution of quotas. The first type of departure would trade off accommodation of refugee choices against the degree of protection provided, perhaps most obviously the rapid access to membership of the state of asylum. The second type of departure would trade off accommodation of refugee choices against the share of other responsibilities owed by the relevant states of asylum, 
whether these responsibilities pertain to other dimensions of the refugee regime or to their share of more general responsibilities of global justice. We should be wary of the first type of departure from a just distribution in which accommodating refugee choices becomes a basis for weakening the protections that are practical expressions of the reasons for valuing refugee choices, namely, to support refugee autonomy through inclusion and integration. This does not entail that such departures can never be justified, only that we should be prima facie sceptical of this type of departure from a just distribution and require compelling contextual justifications for permitting them. (One could, for example, imagine such justifications applying in contexts in which there is good reason to believe that the causes of a refugee flow are ones that the international community is capable of resolving in the short-to-medium term - say, within 2-6 years - and that it has the will do to so.) There are, however, good reasons to endorse the possibility of the second type of departure in which there is a fair redistribution of overall shared responsibilities of justice so that states are not disadvantaged by seeking to accommodate refugee choices more fully than a just distribution of quotas requires.

We can think of this in terms of a model of quota-trading between states constrained by the principle that quotas can be traded only insofar if the trade in question offers a fuller accommodation of refugee preferences. Here it is important to note that a matching system can also be used in an indicative way in the sense that, given refugee and state preferences, the system can simulate the different outcomes under different sets of quota distributions. This both allows the testing of possible trades in terms of refugee preference satisfaction and, hence, identifying the range of legitimate trades - and also provides states with the informational base for fair trading of (part of) their asylum quota in exchange for (part of) their share of, for example, responsibility for immediate refuge. Note that this is not a system for buying or selling refugee quotas, it is rather about allowing states, under an important justice-based constraint, the opportunity to shape the form that their fair share of international responsibility takes: it is best seen as a form of responsibility-trading. Thus, for example, Norway and Japan might wish to focus their efforts on addressing the sources of refugee conflict through, for example, peace and reconciliation work and/or on supporting developing states of immediate refuge in building their human rights and democratic infrastructures rather than in acting as states of asylum - and this would allow that possibility.

\section{Refugee Voice}

Thus far the focus has been on the features of a just global refugee regime considering states as the key international actors, the need for an international 
institution than can impartially assign responsibilities to states, and a way of acknowledging the normative significance of refugee preferences within such distribution of responsibilities. However, states are not the only actors governed through a global refugee compact, the primary addressees of such regime of governance are the refugees themselves - and, as already stressed, refugees are characterised by their loss of political standing in a global political society organised as an international system of states. The entitlement of refugees to have voice with respect to how they are governed, their claim to have a say over the norms, institution and practices of global refugee governance, can be given a wide variety of theoretical justifications. Thus, for examples, liberal arguments may appeal to the fact that important moral interests of refugees are affected by global refugee governance or to the fact that refugees are subject to coercion through global refugee governance; while republicans may point to global refugee governance as a structure of domination insofar as refugees lack authorial or, at least, editorial powers in relation to it. These different accounts may give rise to different views of the kind of claims to inclusion of refugees in shaping or contesting global refugee governance, claims that can be given institutional expression in a variety of ways ranging from, for example, a contestatory court to a 'Refugee Nation' as a representative at the United Nations. It is not my concern here to work through these different arguments or the range of institutions through which they may be expressed. Rather I simply want to note that all of these approaches take the inclusion - in some form or other - of refugee voices to be a necessary condition of the legitimacy of any regime of global refugee governance; and I want to distinguish two levels of engagement of refugee voice in relation to global refugee governance (although these do not exhaust the possibilities).

The first concerns the norms of a global refugee compact, the choices of the principles that global refugee governance should aim to express in its institutions and practices. If the legitimacy of such norms is conditional of their being actually (rather than hypothetically) justifiable to both states and refugees, we face the question of how to design the participation of both parties in the decision-making process in such a way that gives adequate expression to their respective reasons. What is important for this process both in the deliberation between states and in the deliberation between states and refugees is that it meets basic conditions of reasonableness. We can bring this topic into focus by reference to Laden's argument that 'the reasonableness of deliberation depends on the relevance of uptake of proffered reasons' and, more specifically, that deliberation is unreasonable if uptake is rendered irrelevant. ${ }^{37}$ As Laden notes:

37 Anthony Laden, Reasonably Radical (Ithaca: Cornell University Press, 2001), p. 129. 
Two central ways in which uptake can be rendered irrelevant are by ignoring it or assuming it. Ignoring uptake requires having the power to render rejection of a reason irrelevant. In such cases, we exclude others from our deliberations. Their uptake of our reasons has no effect because their rejection could have no effect. Assuming uptake requires being blind to the fact of deep diversity and how it shapes the plurality of political deliberation. In such cases, we assimilate others to our own perspective. We take for granted that because we find a reason authoritative, they will too. ${ }^{38}$

Given that the specific problem we face, since that there are established mechanisms for states to reach agreements through the UN, is how to include refugees within this deliberative process, our central concerns must be to design inclusion to block the power of the assembly of states to engage in ignoring or assuming uptake of reasons. There are, no doubt, a variety of ways in which this could be achieved. For example, we might wish to reflect the relationship between the two parties by having each make proposals to the other, with each party having a veto power such that they are constrained to reach a mutually satisfactory outcome. Thus, we could mirror the assembly of states with an assembly of refugees (chosen through, for example, stratified random selection and provided with training and support from INGOs) who engage in such a to-and-fro negotiation. Alternatively, we might envisage a contestatory court through which refugee organisations could challenge the collective decisions of states concerning global refugee governance. It is not my goal here to recommend a specific design but simply to indicate the kind of conditions that the legitimate imposition of norms on the refugee population should aim to meet.

The design of the institutions and practices of global refugee governance can be distinguished from the general norms of such governance in the specific sense that it is rarely the case that such norms can only be given expression in a single design (for example, the norm of democratic governance can be realized in a variety of practical designs). In this context, refugees not only have a justificatory claim to inclusion as subjects of this regime of governance but also represent an important and continuing epistemic resource for design and redesign issues grounded in their practical experience of the institutions and practices of refugee governance. What is key here is that there are mechanisms of effective communication and accountability through which the epistemic and political standing of refugees with respect to this form of governance can enter into the process of shaping and reshaping the practice of refugee governance. It is also important to note here that refugees may experience their governance 
differently both on the basis of distinct routes to refuge and asylum, and on the basis of their diverse identities and the different ways in which refugee governance has affected them - recall Gibney's point that:

barriers to entry tend to bias access to asylum in richer states to the physically agile (e.g. young adult refugees), the unencumbered (e.g. those not responsible for the caring of children) and those with access to the resources to pay smugglers and others who would facilitate their plight. ${ }^{39}$

How can refugees act as an effective epistemic resource for global refugee governance in evaluating its performance and have access to ways of holding these institutions and practices accountable for their performance? One possibility would be to establish 'refugee juries' or refugee mini-publics' on a regular basis in a variety of sites and at different stages of the refugee journey (in the temporary camps of first refuge and in the states of asylum) in order to provide mechanisms of participation for refugees in the evaluation of refugee governance and require that the UNHCR or other relevant agencies of refugee governance formally respond to the recommendations and/or complaints arising from such bodies. Again, it is not my aim here to recommend a specific mechanism but to highlight the point that securing the claim to legitimacy of global refugee governance provides reasons for developing such vehicles of refugee voice.

\section{Conclusion}

The New York Declaration provides an opportunity to reflect on the limitations of the current refugee regime and the directive assigned to the UNHCR to develop a global refugee compact provides an incentive to consider the normative contours of a just compact and a legitimate regime of global refuge governance. My aim is this essay has been to develop the basis of an account of the shared responsibility of states to refugees and of how the character of that responsibility effects the ways in which it can be fairly shared and how such fair sharing should be enabled. However, it is an important feature of the New York Declaration that it stresses the dignity of refugees and the importance of refugee agency as well as the issues of refugee inclusion and refugee self-reliance. This highlights the need for any adequate normative analysis to move beyond the question of the general obligations that states owe to refugees to consider ways in which refugee choices and refugee voice can be given appropriate standing with the global governance of refuge. In the second section, I provided an argument for the normative significance of refugee's reasons for choosing states of asylum and

39 Gibney (2015), p. 452. 
linked this to consideration of a refugee matching system and to refugee quota trading conceived as responsibility-trading. I argue that, subject to specific constraints, both a refugee matching system and responsibility trading can be justified as ways of acknowledging the normative significance of refugee choices. In the final section, I turn to the issue of the inclusion of refugee voice in relation to the justification of the norms of refugee governance and in relation to the institutions and practices of refugee governance through which those norms are given practical expression. My limited purpose in this section was to argue that the inclusion of refugee voice in these two respects was central to the legitimacy of global refugee governance and to provide some indicative examples of how such inclusion might be designed. The considerations gathered in this essay represent one beginning for reflection on a just and legitimate regime of global refugee governance that is aimed at contributing to the dialogue initiated by the New York Declaration.

David Owen

Professor of Social and Political Philosophy

Department of Economic, Social and Political Sciences

University of Southampton

email:dowen@soton.ac.uk

the global justicenetuork 